\title{
EFFECT OF PROPRIOCEPTIVE TRAINING EXERCISES ON BALANCE IN HEALTHY INDIVIDUALS
}

\author{
Lyubomira Sazdova
}

National Sports Academy "Vassil Levski", Sofia, Bulgaria

\begin{abstract}
Introduction: Balance and maintenance of postural control is a multisystem process requiring input from the vestibular, visual, and proprioceptive systems. It is an important component of motor performance tasks.

The aim of the report is to present the effect of proprioceptive training exercises on static and dynamic balance on healthy individuals.

Methodology: The study was conducted on 16 subjects, mean age 23.6, all active athletes. The specialized training program included proprioceptive exercises, performed on stable and unstable surfaces. Progression was made by incorporating upper and lower extremities movements and functional activities. Balance performance was evaluated using static (One leg stance) and dynamic (Y-balance test) balance tests. All participants were assessed prior to start the exercise program and at the follow-up - at 1st month. To estimate the results statistical analysis with means and $P$ value was used.

Results: The results of application of the specialized proprioceptive exercises showed statistically significant improvement in postural control and static and dynamic balance.

Conclusions: Physiological and clinical benefits of balance training could be utilized to enhance the athletic performance and to decrease the level of low extremity injuries.
\end{abstract}

Key words: proprioceptive training, balance, healthy individuals

\section{INTRODUCTION}

Balance is a multisystem process, which integrates input from the visual, tactile, proprioceptive and vestibular systems. Balance and postural control are important components of motor performance and are involved in nearly every movement that is performed in life. Information regarding body position, gravity, musculosekeletal activity, tactile and visual feedback, and other input provides the nervous system information required to maintain balance during daily activities and sport performance (Sefton et al, 2011).

There are two main types of balance - static and dynamic. Static balance is defined as maintaining postural equilibrium while holding the body in a stationary position and dynamic balance is maintenance of postural equilibrium while parts of the body are moving (Jaffri et al, 2017).

Balance training interventions have recently increased their popularity in rehabilitation as well as in performance enhancement. Most research are related to sport injuries and athletic performance in younger age (Kidgell et al, 2007; McKeon, Hertel, 2008; McKeon et al, 2008; Webster, Gribble, 2010), but some concern changes in systems, controlling balance and the effect of proprioceptive training in older population (Rogers et al, 2013).

Several studies indicate that balance training produces improvements in measures of postural control in patients with CAI (Kidgell et al, 2007; McKeon, Hertel, 2008). In a systematic review of Webster K, Gribble P (2010) authors concluded that functional rehabilitation intervention is associated with improved ankle stability for both postural control and self-reported function. A study of McKeon et al (2008), utilizing four weeks of balance training in individuals with CAI, also revealed improved self-reported function and static and dynamic postural control.

Rogers et al (2013) presented a balance training program for older athletes, based on Sensorimotor Training (SMT). The authors believe that SMT should become a part of the regular training for the aging athlete, and its implementation is crucial in addressing the growing number of older athletes.

The aim of this report is to present the effect of proprioceptive training exercises on static and dynamic balance on healthy individuals. 


\section{METHODOLOGY}

The study was conducted on 16 subjects ( 9 male, 7 female), mean age $23.6 \mathrm{yr}$ (age range 21 -26), all active athletes, with no prior history of lower extremity injury, at least 6 months prior to participation in the study. Balance performance was evaluated using static (One Leg Stance (OLS) and dynamic (Y-balance test) balance tests. All participants were assessed prior to start the exercise program and at the follow-up - at 1st month.

To evaluate static balance (OLS), the participants were instructed to stand on one leg with eyes closed, hands resting at the waist level. OLS duration was measured in seconds (sec), and $30 \mathrm{sec}$ was accepted as a norm.

The Y balance test (shortened version of the Star Excursion Balance Test) was used for assessment of the dynamic balance. For testing our participants we used the procedure, described by Plisky et al (2009). While maintaining single leg stance, the subject was asked to reach with the free limb in the anterior, posteromedial, and posterolateral directions, in relation to the stance foot. The testing order was three trials standing on the right foot reaching in the anterior direction (right anterior reach) followed by three trials standing on the left foot reaching in the anterior direction. This procedure was repeated for the posteromedial and the posterolateral reach directions. The specific testing order was right anterior, left anterior, right posteromedial, left posteromedial, right posterolateral, and left posterolateral. The greatest successful reach distance $(\mathrm{cm})$ for each direction was used for analysis of the reach distance in each direction (Pliski et al, 2009). The data were analyzed for each subject for the right limb in the anterior, posterolateral, and posteromedial reach directions. Means and stan- dard deviations were calculated for the reach distance in each direction. A dependent-sample t-test was used, to determine if there was a difference between results of start testing and after 4 week training, and the significance level $(\alpha)$ was considered at $<.05$.

The proprioceptive training program included special balance exercises. The goal of each exercise was to be performed with appropriate postural stabilization. To activate postural mechanisms labile surfaces (such as stability trainers and balance boards) were used. The exercises progressed by decreasing the base of support from double to single limb stance. The participants were challenged by adding trunk perturbations, movements of the extremities, and Therabands resistance. The visual and vestibular systems were challenged by performing the exercises with closed eyes and incorporating head movements. The balance training exercises progressed by incorporating functional activities and sports specific tasks. The participants performed the proprioceptive program at least 4 times per week.

\section{RESULTS}

Mean, standard deviation, and mean difference of One Leg Stance test are reported in Table 1. The results indicated statistically significant difference in time to stand on both left or right lower limb preand post-training $(\alpha<.01)$. On average data showed $18.63 \mathrm{sec}$. for left and $23.44 \mathrm{sec}$. for right leg before to start the training program, and $26.19 \mathrm{sec}$. and $28.94 \mathrm{sec}$. respectively, after 4 weeks exercising (Table 1, Figure 1). This finding suggested that maintenance of static balance could be successfully improved by implementation of specialized proprioceptive training exercises.

Table 1. Results of One Leg Stance Test

\begin{tabular}{|c|c|c|c|c|c|c|c|}
\hline & \multicolumn{2}{|c|}{ Start } & \multicolumn{2}{|c|}{$1 \mathrm{~m}}$. & \multirow{2}{*}{$\Delta X$} & \multirow[b]{2}{*}{$t$} & \multirow[b]{2}{*}{$\alpha$} \\
\hline & $X$ & $S$ & $X$ & $S$ & & & \\
\hline Left leg & 18.63 & 7.15 & 26.19 & 4.97 & 7.56 & 3.47 & $\alpha<0.01$ \\
\hline Right leg & 23.44 & 6.44 & 28.94 & 1.81 & 5.50 & 3.29 & $\alpha<0.01$ \\
\hline
\end{tabular}

Legend: $X$ - mean value in sec.; $S$ - standard deviation; $\Delta X$ - mean difference; $t$ - Student's $t$-test ; $\alpha$ - significance level. 


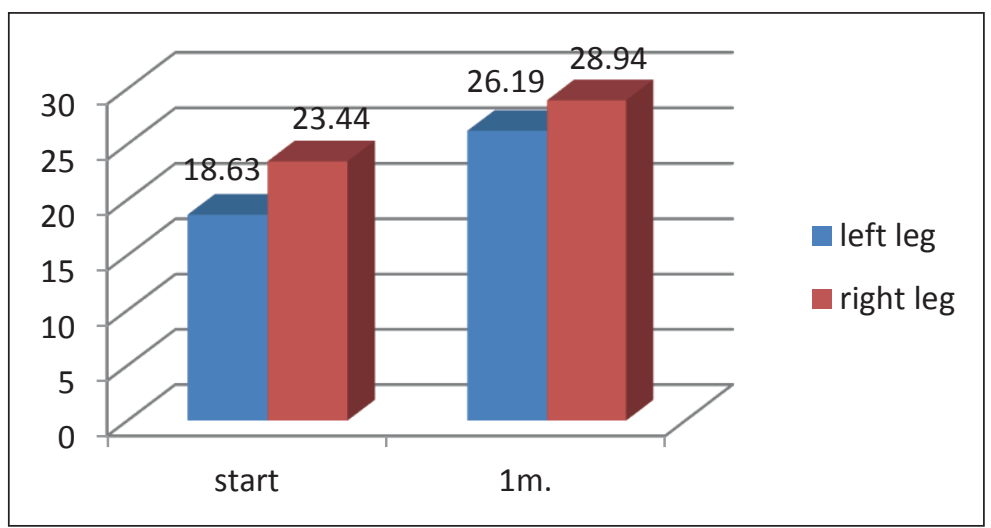

Figure 1. Results of One Leg Stance Test

Analysis of the change of reach direction of Y-bal- medial directions. There was no significant differance test revealed significant difference between ence for anterior reach, neither the right nor the left pre-training and post-training results for both left lower limb $(\alpha>.05)$. A summary of data is presented and right lower limbs in posterolateral and postero- on Tables 2, 3 and Fig. 2, 3.

Table 2. Results of Y-Balance test - left reach distance.

\begin{tabular}{|c|c|c|c|c|c|c|c|}
\hline \multirow{2}{*}{$\begin{array}{l}\text { Left reach } \\
\text { distance }\end{array}$} & \multicolumn{2}{|c|}{ Start } & \multicolumn{2}{|c|}{$1 \mathrm{~m}}$. & \multirow{2}{*}{$\Delta X$} & \multirow{2}{*}{$t$} & \multirow{2}{*}{$\alpha$} \\
\hline & $X$ & $S$ & $X$ & $S$ & & & \\
\hline Anterior & 61.06 & 6.89 & 65.50 & 7.17 & 4.43 & 1.78 & $\alpha>0.05$ \\
\hline Posteromedial & 81.44 & 5.21 & 86.75 & 4.00 & 5.31 & 4.04 & $\alpha<0.001$ \\
\hline Posterolateral & 80.13 & 3.32 & 85.50 & 2.66 & 5.37 & 5.05 & $\alpha<0.001$ \\
\hline
\end{tabular}

Legend: $X$ - mean value in cm; $S$ - standard deviation; $\Delta X$ - mean difference; $t$ - Student's $t$-test ; $\alpha$ significance level.

Table 3. Results of Y-Balance test - right reach distance.

\begin{tabular}{|c|c|c|c|c|c|c|c|}
\hline \multirow{2}{*}{$\begin{array}{l}\text { Right reach } \\
\text { distance }\end{array}$} & \multicolumn{2}{|c|}{ Start } & \multicolumn{2}{|c|}{$1 \mathrm{~m}}$. & \multirow{2}{*}{$\Delta X$} & \multirow{2}{*}{$t$} & \multirow{2}{*}{$\alpha$} \\
\hline & $X$ & $\mathbf{S}$ & $X$ & $\mathbf{S}$ & & & \\
\hline Anterior & 64.93 & 5.26 & 68.37 & 5.15 & 3.44 & 1.87 & $\alpha>0.05$ \\
\hline Posteromedial & 82.37 & 3.16 & 87.85 & 2.43 & 5.48 & 4.09 & $\alpha<0.001$ \\
\hline Posterolateral & 81.18 & 5.84 & 86.85 & 5.43 & 5.56 & 2.79 & $\alpha<0.01$ \\
\hline
\end{tabular}

Legend: $X$ - mean value in cm; $S$ - standard deviation; $\Delta X$ - mean difference; $t$-Student's $t$-test ; $\alpha$ - significance level

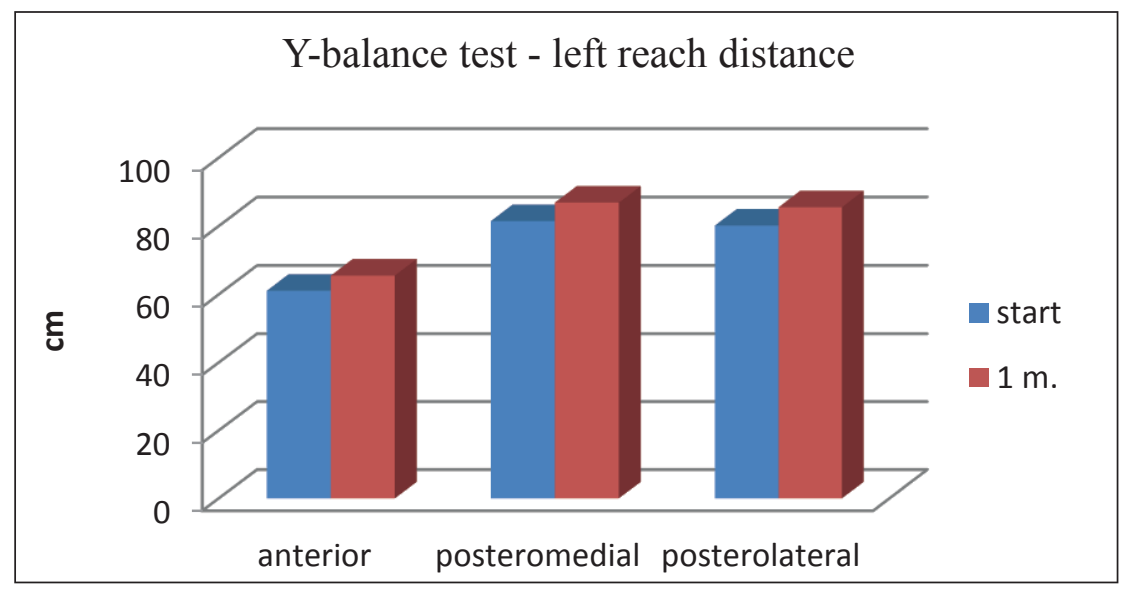

Figure 2. Results of Y-balance test - left reach distance 


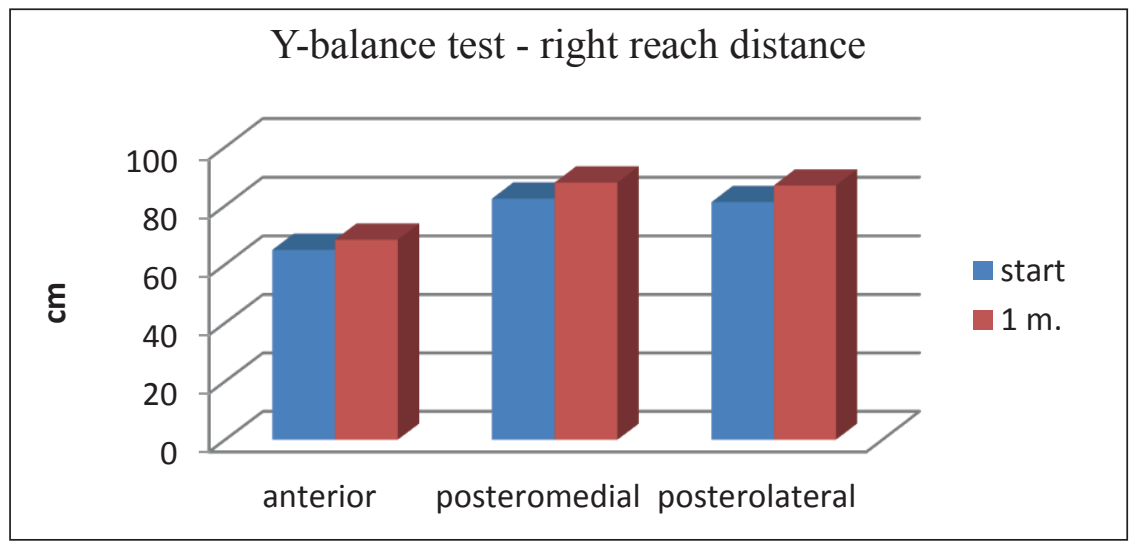

Figure 3. Results of Y-balance test - right reach distance

On average, initial data for the left leg showed 61.06 $\pm 6.89 \mathrm{~cm}$ anterior reach, $81.44 \pm 5.21 \mathrm{~cm}$ posteromedial reach, and $80.13 \pm 3.32 \mathrm{~cm}$ posterolateral reach. After 4 weeks training, anterior reach improved to $65.50 \pm 7.17 \mathrm{~cm}$, posteromedial - to 86.75 $\pm 4.00 \mathrm{~cm}$. and posterolateral - to $85.50 \pm 2.66 \mathrm{~cm}$. For the right leg reach the results improved from $64.93 \pm 5.26 \mathrm{~cm}$ for anterior, $82.37 \pm 3.16 \mathrm{~cm}$ for posteromedial and $81.18 \pm 5.84 \mathrm{~cm}$ for posterolateral reach to $68.37 \pm 5.15 \mathrm{~cm}, 87.85 \pm 2.43 \mathrm{~cm}$ and $86.85 \pm 5.43 \mathrm{~cm}$ respectively. Comparison of data showed no significant difference between pre- and post-training mean anterior reach, but in many of the subjects anterior reach asymmetry between left and right side was greater than $4 \mathrm{~cm}$, which according to Plisky et al (2006) is connected with increased risk of injury of the lower extremities.

\section{CONCLUSION}

The results of our study provide initial evidence to suggest that the specialized proprioceptive exercises could improve both static and dynamic balance. Physiological and clinical benefits of balance training could be utilized to enhance the athletic performance and to decrease the level of low extremity injuries.

Our report has some limitations. First, the study was conducted on relatively small contingent and second - it involved individuals with different level of physical activity. Future studies should also utilize a similar, standardized testing protocol so that results may be compared across studies.

\section{REFERENCES}

Jaffri, AH., Newman, TM., Smith, BI., Miller, SJ. (2017). The dynamic leap and balance test (DLBT): A test-retest reliability study. Int J Sports Phys Ther, 12(4): 512-519. Kidgell, DJ., Horvath, DM., Jackson, BM., Seymour, PJ.
(2007). Effect of six weeks of dura disc and mini-trampoline balance training on postural sway in athletes with functional ankle instability. J Strength Cond Res, 21(2):466-469.

McKeon, PO., Hertel, J. (2008). Systematic review of postural control and lateral ankle instability, part II: is balance training clinically effective? J Athl Train, 43(3):305-315.

McKeon, PO., Ingersoll, CD., Kerrigan, DC. et al (2008). Balance training improves function and postural control in those with chronic ankle instability. Med Sci Sports Exerc, 40(10):1810-1819.

Plisky, P., Gorman, P., Butler, R., Kiesel, K., Underwood, F., Elkins, B. (2009). The Reliability of an Instrumented Device for Measuring Components of the Star Excursion Balance Test. N Am J Sports Phys Ther, 4(2): 92-99.

Plisky, P., Rauh, M., Kaminski, T., Underwood, F. (2006). Star Excursion Balance Test as a predictor of lower extremity injury in high school basketball players. $J$ Orthop Sports Phys Ther, 36: 911-9.

Rogers, M., Page, P., Takeshima, N. (2013). Balance training for the older athlete. Int $J$ Sports Phys Ther, 8(4): 517-530.

Sefton, JM., Yarar, C., Hicks-Little, CA., Berry, JW., Cordovam ML. (2011). Six weeks of balance training improves sensorimotor function in individuals with chronic ankle instability. $J$ Orthop Sports Phys Ther, 41(2):81-9.

Webster, KA., Gribble, PA. (2010). Functional rehabilitation interventions for chronic ankle instability: a systematic review. J Sport Rehabil, 19(1):98-114.

Corresponding author: Lyubomira Sazdova, PhD Associate Professor in Theory and Methods of kinesitherapy department National Sports Academy "Vassil Levski" Sofia 1000, Gurgulyat 1 Str. E-mail: 1_sazdova@abv.bg 